\title{
REDES, NO-LUGARES, NATURALEZA
}

\section{La arquitectura de la ciudad global \\ Eduardo Prieto \\ Biblioteca Nueva. Madrid, 2011 \\ 237 páginas, $18 €$}

$\mathrm{L}$

a mejor descripción que puede hacerse de La arquitectura de la ciudad global es atendiendo a la biografía de su autor: arquitecto y filósofo. Desde ese punto de vista híbrido (o no tanto) afrontará diferentes cuestiones con respecto al dónde vivimos. No debe sorprender por lo tanto encontrar a Koolhaas y a Heidegger en la misma frase, ni a Le Corbusier y Walter Benjamin compartiendo párrafo. Eduardo Prieto nos propone pensar no tanto «dónde» vivimos como «por qué» lo hacemos allí, y «cómo» hemos llegado a vivir así. Nos propone así el autor un recorrido por la historia del pensamiento $\mathrm{y}$ su reflejo en las ciudades, que son el lugar donde cada vez vive un mayor porcentaje de la población.

He intentado apuntar las ideas principales de lo que es un conjunto de ensayos a veces muy diversos y en los que el autor pasa de una idea

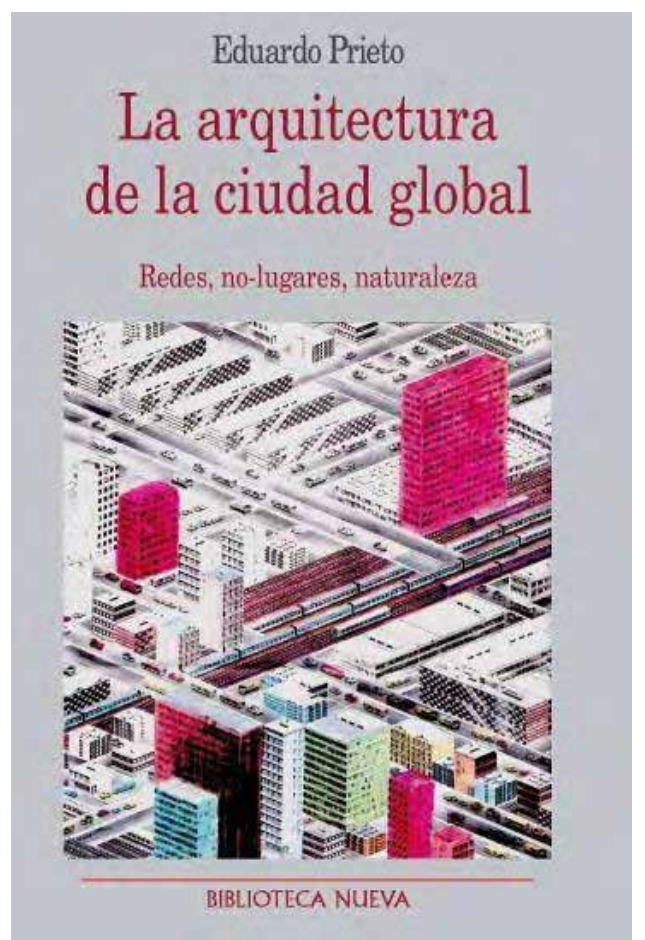

a otra rápidamente. Pido disculpas si esta reseña resulta a veces poco coherente o fragmentada, aunque puedo asegurar que el ensayo que intenta describir no lo es.

La obra está estructurada en tres grandes capítulos: Redes, No-lugares y, por último, Naturaleza. En cada uno de ellos Eduardo Prieto presenta 
hechos y características fundamentales que describen las ciudades en las que habitamos.

El primero de estos grandes capítulos lleva el nombre de Redes y en él el autor nos explica la importancia de lo urbano ante la enorme (y creciente) cantidad de individuos que habitan en ciudades. La globalización ha migrado a la red, siendo la extensión urbana digital, lo que viene a significar que las ciudades, además de estar unidas por autopistas, aeropuertos y ferrocarriles lo están por la red. La red, que ha sido la utopía de este siglo, como la utopía de la industrialización lo fue en el xx, la «era de la máquina», la «no nacida de madre», como diría Apollinaire, ha sido sustituida por la era digital, llena también de sueños de liberación: sólo hace falta leer el optimismo de Yoneji Masuda (1984) para apercibirse de cuánto tenía de utopía (etimológicamente un doble significado en

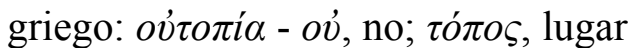
= 'lo que no está en ningún lugar'- $\mathrm{y}$ por el otro $\varepsilon \dot{\tau} \tau o \pi i \alpha$ - $\varepsilon \dot{v}$, buen; $\tau o ́ \pi o \varsigma$, lugar = 'buen lugar'- ). La utopía digital ha devenido en pesadilla panóptica, dice Prieto, poniendo como ejemplo la vigilancia de cámaras en ciudades, o el voluntariado estadounidense que ayuda espontáneamente y desde su casa en la vigilancia de la frontera con México. Pone también en cuestión el valor de las redes sociales como herramientas de cambio de lo público, al ir empleándose en el ámbito privado de modo mayoritario en lugar de colaborar en la creación de un espacio público digital. Incluso las llamadas ciudades inteligentes, que iban a hacernos las cosas más fáciles, más cómodas y más ecológicas, se emplean al final en un control del poder que desmiente la supuesta neutralidad de la técnica y que ya hubieran querido los mayores dictadores de la historia. Los recelos de Heidegger contra la supuesta «neutralidad» de la técnica parecen estar justificados.

También hablará Prieto de las llamadas ciudades in vitro. Estas urbes son aquellas que nacen de la nada por una decisión política, tanto antiguas (Alejandría o San Petersburgo) como modernas (Astana), en un batiburrillo de estilos sólo guiado por la necesidad de sumar prestigio a base de arquitectos de fama. Ahí la ciudad se comporta como un ejemplo perfecto de generación de espectáculos debordianos, ya que de tal modo se debe considerar una obra de arquitecto-estrella: como un espectáculo. 
La segunda de las secciones lleva por título: No-lugares. Va más allá de la definición de Marc Augé (2008), que ya se considera tan clásica como discutida: «El no lugar es un espacio sin capital simbólico». Volveremos a Augé más adelante. El autor aborda la relación del célebre arquitecto Rem Koolhaas con el caos. El caos como una especie de crecimiento orgánico, rizomático, de las ciudades. El caos posmoderno aparecerá como respuesta al panóptico moderno (moderno en sentido histórico, claro). Del vigilado panóptico al crecimiento libre posmoderno. El balanceo hacia el otro extremo, o intento de contrarrestar la máquina moderna con el caos artístico propugnado por la Escuela de Fráncfort, y su oposición a la tiranía técnica con el valor del arte. Y, sin embargo, hay un contrasentido inherente en el hecho de que un arquitecto fabrique el caos. De hecho, un Koolhaas tardío, mucho después del de Delirio de Nueva York, hablará en cambio de «ciudades genéricas», cargando contra la excesiva semejanza de las urbes modernas y entrando en contradicción con lo espontáneo, ya que por lo común los controladores de la ciudad buscan lo singular y lo icónico (París, Barcelona, etc.). Lo genérico, lo que hace que todas las ciudades sean muy parecidas, deviene como consecuencia capitalista de la globalización digital. Por lo tanto... ¿espontaneidad o planificación?

Y construir. ¿Construir cómo? ¿Y qué? El análisis filosófico de la construcción proviene en gran medida del «construir, habitar, pensar» de Heidegger. Cuestiona el filósofo por supuesto la técnica moderna, que puede construir pero no necesariamente $h a-$ cer habitable una construcción (básicamente el viejo dilema heideggeriano entre téchne y técnica moderna, sabiduría frente a conocimiento instrumental). Sólo preguntando a la técnica podemos llegar a un episteme desvelador (desocultar) de la verdad. Y sólo así podemos conocer y no sólo fabricar. Prieto lo ilustra con el ya clásico ejemplo del puente. La casa para Heidegger como «Casa del Ser», hecho en el que incidirá también Gastón Bachelard en su Poética del espacio. Asimismo, el espacio es un don otorgado por el lugar, y no al revés (espacio como abstracción genérica, lugar como concreto con valor simbólico). El construir de verdad lleva a crear lugares, y no únicamente a domesticar el espacio. Es, en palabras del autor del libro, un crear ontológico. Otro (si no el mayor) de los grandes arquitectos de la historia, Le 
Corbusier, creía que mediante la casa se podía llevar a cabo una «educación social» que eliminara la alienación de la sociedad provocada por la vida en las ciudades. Era la suya, de algún modo, una arquitectura moralizada y pedagógica: él y sus epígonos creían firmemente que la buena arquitectura crearía buenos ciudadanos, según explica Robert Hughes (1980). Sin embargo, la casa no tiene más pretensión que la de instrumento moralizador. Coincide en esto con Heidegger: la necesidad de cuidar ese hogar, bien ancestral en el filósofo alemán, bien educativo en el arquitecto suizo. Asimismo, también están de acuerdo en la vuelta a la naturaleza. No por nada Le Corbusier hablará de «hábitat» y no de «lugar».

Sobre el «Lugar vs. Espacio» es también relevante la opinión de Hannah Arendt (1985) al hablar de lo que ella llamó inter-est, que es lo que hace posible que la gente se relacione en función de lo que dicen o hacen, y no sólo por lo que son en función de su pertenencia a un determinado lugar, (análisis éste que se podría extender a cualquier nacionalismo). La persona del lugar incorpora al lugar en su ser. En cambio, el ciudadano (de la ciudad) se construye a sí mismo, y no al lugar. Existe pues una especie de tiranía de valores simbólicos que atrapan al lugareño, mientras que el urbanita desarraigado se ve obligado, privado de un marco conceptual-simbólico, a construirlo él mismo.

Eduardo Prieto habla también, como decía anteriormente, de un término muy conocido ya, el no-lugar de Marc Augé, en gran medida deudor de su maestro Michel de Certeau. El no lugar es lo opuesto a lugar en el sentido en el que hablábamos anteriormente con Heidegger y Arendt. El no-lugar suele describirse como los lugares de tránsito: aeropuertos, estaciones... aunque, siendo Augé antropólogo, para Augé serán los «espacios no simbolizados del planeta». Los no-lugares son, también, una de las características de eso que llamamos sobremodernidad. Hospitales, estaciones, hoteles, aeropuertos son no-lugares. Sin embargo, Prieto nos dirá que esos espacios de la red pertenecen, en su gran crecimiento, a lo moderno. Evoca sin duda los espacios de paso y estaciones futuristas a lo Sant'Elia (arquitecto futurista que, colmado de testosterona como sus compañeros, corrió voluntario a morir en la guerra) y los asimila a los no-lugares. Pero creo que hay netas diferencias. En primer lugar, los primeros pertenecen a la utopía de la 
máquina, y los segundos ya han trascendido a la utopía de la red. En cierto modo se ha vuelto a un pensamiento medieval, sólo que en lugar de tener presente en el día a día la metafísica cristiana tenemos la metafísica de la red. Y en segundo lugar (y dejando aparte las críticas epistemológicas al concepto de Augé realizadas por Maximiliano Korstanje (2008), existe un habitar de los no-lugares que los carga de valor simbólico. Adolescentes que viven en centros comerciales, expulsados del sistema que viven en estaciones, trabajadores de esos lugares. Hasta se genera una cultura del lugar (Mallrats [1995], de K. Smith, La terminal [2004], de S. Spielberg por poner dos ejemplos). ¿Podemos hablar de no-lugar, entonces? No. Y tampoco es un no-lugar comparable a los no-lugares modernos por los argumentos ofrecidos anteriormente.

El crecimiento y la expansión del no-lugar plantea asimismo una vuelta de cierto nacionalismo cultural, a la reclamación de la identidad y a todas las claves simbólicas que se utilizan en la construcción de lo que hemos llamado lugares. Se reivindica lo simbólico para separarlo de lo genérico. Cuestión aparte sería si la creación de una «marca ciudad» con intención identitaria, acaba convirtiendo, por acción del capitalismo globalizante y voraz, lo que era un lugar como Barcelona en un no-lugar de tránsito exclusivamente para turistas.

La tercera de las secciones la dedica el autor a la Naturaleza. Bien es cierto que ésta ya ha surgido en capítulos previos, pero en ella se encuentran diferentes enfoques sobre su relación con el habitar: la apropiación capitalista de la naturaleza, que queda reducida a un objeto de mercancía; la visión panóptica a ojo de Google de los territorios, que permite a cualquiera desde su casa observar la base rusa de submarinos de Polyarny, y ha cambiado la visión del mundo más de lo que lo hizo Mercator, la importancia conceptual del jardín o su falta, etc.; y en un brillante epílogo tratará la figura del flâneur digital y su comparación con el flâneur moderno que todos conocemos ya. Uno deriva por la ciudad, el otro lo hace por la red, casi con la misma metodología, que no es sino ausencia de toda metodología. El ojo inquieto que Baudelaire, Benjamin y Walser describieran tan bien en sus obras.

Y me he dejado mil cosas, hay mucho más en la obra de Prieto de lo que puedo nombrar en estas páginas. Os recomiendo leerlo. Con tiempo, 
una buena biblioteca a mano y un lápiz para subrayar y anotar. Pocas veces puede ir uno de la mano de un guía tan correcto y conceptualmente bien armado como él para entender el cómo y el porqué de dónde vivimos, de nuestros espacios y nuestros lugares.

Es difícil en una obra tan completa extrañar algo, sólo he echado de menos menciones a David Harvey, que dice lo mismo que Koolhaas desde una clave marxista (además de su Disneyzación de las ciudades, semejante a las «Ciudades genéricas»), y alguna mención a nuevas propuestas de organización subversiva de las ciudades como el ya clásico TAz de Hakim Bey, o las reflexiones de Manuel Delgado (antropólogo como Augé y Harvey). Pero sin duda se alejaría un tanto de la perspectiva más clásica de la obra. No os dejará indiferentes.

\section{Enrique Salóm,}

Historiador y activista cultural

\section{Bibliografía recomendada}

Adorno, Th. W. (2007): Dialéctica de la Ilustración, Akal, Madrid.

Arendt, H. (2005): La condición huma$n a$, Paidós, Barcelona.
Augé, M. (2008): Los no lugares. Espacios del anonimato, Gedisa, Barcelona.

Bachelard, G. (2005): La poética del espacio, Fondo de cultura económica, México.

Certeau, M. D. (1990): L'Invention $d u$ quotidien, Gallimard, Paris.

Debord, G. (1999): La sociedad del espectáculo, Pre-textos, Valencia.

Delgado, M. (2011): El espacio público como ideología, Catarata, Madrid.

- (2007): Sociedades Movedizas, Anagrama, Barcelona.

Foucault, M. (1999): Obras esenciales, Paidós, Barcelona.

Harvey, D. (2012): Ciudades rebeldes. Del derecho a la ciudad a la revolución urbana, Akal, Madrid.

Hughes, R. y D. L. Richardson (director) (1980): The shock of the future, Time-Life Films- BBC (Serie de televisión), GB.

Hughes, R. (1991): El impacto de lo nuevo. El arte del siglo $X X$, Galaxia Gutemberg-Círculo de lectores, Barcelona.

KoolhaAs, R.; S. Boeri y S. KwiNTER (2011): Mutations, ACTAR, Bordeaux.

Koolhaas, R. (2012): Delirio de Nueva York, Gustavo Gili, Barcelona.

- (2011): La Ciudad genérica, Gustavo Gili, Barcelona.

Korstanje, M. (2008): «Meditaciones críticas: Turismo, Temor y Modernidad», Revista Digital A Parte Rei, 60 (noviembre). 
LeFEBVRe, H. (1970): La Revolución urbana, Alianza, Madrid.

Masuda, Y. (1984): La sociedad informatizada como sociedad post-industrial, Fundesco-Tecnos, Madrid.

Miessen, M. y S. Basar (2009): ¿Alguien dijo participar?, DPR-Barcelona, Barcelona.

Rossi, A. (2013): La arquitectura de la ciudad, Gustavo Gili, Barcelona.

Sмiтн, K. (director) (1995): Mallrats, Universal Pictures, EEUU.

SPIELBerg, S. (director) (2004): La terminal, Dreamworks, EEUU. 
